\title{
Non-Small Cell Lung Cancer: Therapeutic and Evolutionary Aspects in Cote d'Ivoire
}

\author{
Touré Moctar*, Kouassi Kouamé Konan Yvon, Séka Evrard Narcisse, Traoré Kadjatou, \\ Traoré Asmaho Danielle, Odo Bitti Addé, Oumou Kimso, Kagambega Arsène Gaëtan, \\ Adoubi Innocent
}

Oncology Department of the Treichville University Hospital, Abidjan, Cote d'Ivoire

Email: *moukitoure@yahoo.fr

How to cite this paper: Moctar, T., Yvon, K.K.K., Narcisse, S.E., Kadjatou, T., Danielle, T.A., Addé, O.B., Kimso, O., Gaëtan, K.A. and Innocent, A. (2018) Non-Small Cell Lung Cancer: Therapeutic and Evolutionary Aspects in Cote d'Ivoire. Advances in Lung Cancer, 7, 1-8.

https://doi.org/10.4236/alc.2018.71001

Received: March 3, 2018

Accepted: March 27, 2018

Published: March 30, 2018

Copyright $\odot 2018$ by authors and Scientific Research Publishing Inc. This work is licensed under the Creative Commons Attribution International License (CC BY 4.0).

http://creativecommons.org/licenses/by/4.0/

cc) $\underset{\mathrm{EY}}{\mathrm{EY}}$ Open Access

\begin{abstract}
Non-small cell lung cancer (NSCLC) is a heterogeneous group of malignancies including squamous cell carcinoma, adenocarcinoma, bronchioloalveolar carcinoma and large cell carcinoma. They are known to be of poor prognosis, despite a better understanding of bronchial oncogenesis. This descriptive retrospective study carried out over three years (January 2013 to December $31^{\text {st }}$, 2016) at the Oncology Department of the Treichville University Hospital in Abidjan was aimed to assess the efficacy of new treatments for NSCLC in Cote d'Ivoire and to specify their benefit in terms of quality of life, comfort and overall survival. This 77 patients study, found that NSCLC, the most frequent of which is squamous cell carcinoma, occurs in relatively young subjects, smokers (91\%) diagnosed at a locally advanced or metastatic stage (89\%). Cisplatin base multi-drug chemotherapy was mostly used (71\%). Combined all treatments, there was a significant clinical gain. However, no complete response was observed. Hematological and digestive toxicities were seen in more than $30 \%$ of cases. Overall survival was of 9 months on average. This study is an advocate to optimize primary prevention policies for a cancer with poor prognosis despite the development of new treatments such as target therapies.
\end{abstract}

\section{Keywords}

Non-Small Cell Lung Cancer, Treatment, Evolution

\section{Introduction}

Broncho-pulmonary Cancer (BPC) is characterized by a cellular heterogeneity, of which non-small cells cancer is ranked first [1]. This entity is considered to be 
of poor prognosis with high mortality rates in both Western and African countries [2] [3]. Its treatment has improved considerably over the past ten years due to a better understanding of bronchopulmonary oncogenesis [4]. Newly developed molecules have shown definite efficacy in terms of response, overall survival and disease-free survival in Western series [4]. However, these molecules are hardly accessible to the majority of our patients because of the lack of financial means and/or the non-availability of these molecules. The goal of this study was to evaluate the therapies used for Non-Small Cell lung Cancer (NSCLC) in Cote d'Ivoire by identifying their benefits in terms of quality of life, tolerance and overall survival.

\section{Materials and Method}

This was a retrospective, non-comparative descriptive study of 77 patients with non-small cell lung cancer. This study was done over a three year period (January 2013 to December $\left.31^{\text {st }}, 2016\right)$ at the Oncology Department of the Treichville University Hospital of Abidjan. All patients received both specific and non-specific treatment. Data collection was based on clinical records (epidemiological, clinical and therapeutic characteristics) and, pathology reports (bronchial biopsy specimens and/or surgical specimens) obtained in the various University Hospital laboratories of Abidjan. Every patient had benefited from a pre-therapeutic assessment including an extended assessment (chest, abdominal and pelvic scan, abdominal ultrasound) and a biological assessment ( $\mathrm{CBC}$, liver and renal functions, calcemia) so as to minimizing possible treatment toxicities. At the end of this process, staging was established with the TNM system (2009) [5]. The treatment instituted was either surgery or chemotherapy with cisplatin base regiments. Some patients had received exclusively symptomatic treatment (palliative radiation therapy, symptomatic care). For patients receiving chemotherapy, hyperhydration with added magnesium and potassium was necessary. The anticancer drugs were administered by either peripheral intravenous infusion or through an implantable venous access device and this every 21 days.

The response to treatment was evaluated according to the Recist 2000 criteria which define complete response (CR), partial response (PR), tumor stabilization (ST) and tumor progression (PT) [6]. Tolerance was evaluated according to WHO criteria and overall survival according to the Kaplan Meier method [7].

\section{Results}

During our study period, 77 patients met the inclusion criteria. The average age was of 53 years with extremes of 41 and 70 years (Table 1). Male subjects were predominant (75\% of cases) (Table 1). Tobacco abuse was found in $91 \%$ of cases (Table 1). Occupational exposure and family history were found in only $3 \%$ of cases each (Table 1). The clinical signs were polymorphic, chest pain being the major symptom in $87 \%$ of cases (Table 2). In $22 \%$ of cases, a paraneoplastic syndrome was found. The most common histological types were squamous cell 
carcinoma and adenocarcinoma in $61 \%$ and $25 \%$, respectively (Table 2). $89 \%$ of our patients consulted at a locally advanced and metastatic stage (Table 2).

The most commonly used therapeutic modality was chemotherapy in approximately $71 \%$ of cases. The most commonly instituted protocol combined Taxane and Platine in $27 \%$ of cases. Target therapies were only used in $4 \%$ of cases (Table 3). All treatments combined, there was a significant clinical gain (Table 3). However, no complete response was observed. On the other hand, stabilization was observed especially with the combination Surgery-Chemotherapy

Table 1. General characteristics of the population.

\begin{tabular}{cccc}
\hline Population Characteristics & & Number $(\mathbf{N}=\mathbf{7 7})$ & $\%$ \\
Age Average & F & 53 years $[41-70]$ & \\
Gender & M & 19 & 25 \\
& Low & 58 & 75 \\
Socio-economic level & Average & 13 & 17 \\
& High & 33 & 43 \\
Tobacco abuse & & 31 & 40 \\
Alcohol abuse & & 70 & 91 \\
Professional exposure & & 48 & 62 \\
Family history & & 2 & 2.6 \\
\hline
\end{tabular}

Table 2. Clinical and pathological Characteristics.

\begin{tabular}{|c|c|c|c|c|}
\hline \multicolumn{2}{|c|}{ Clinical and Pathological Characteristics } & \multicolumn{2}{|c|}{ Number $(\mathrm{N}=77)$} & \multirow{2}{*}{$\begin{array}{c}\% \\
35.07\end{array}$} \\
\hline \multirow{3}{*}{ WHO Performance status } & 1 & & & \\
\hline & 2 & & & 40.25 \\
\hline & 3 & & & 24.68 \\
\hline Chest pain & & & & 87 \\
\hline Dyspnea & & & & 17 \\
\hline Hemoptysis & & & & $4 \%$ \\
\hline Association of 2 or 3 Symptoms & & & & 30 \\
\hline \multirow[t]{2}{*}{ Paraneoplasic Syndromes } & & & & 22 \\
\hline & Squamous Cell Carcinoma & & & 61 \\
\hline \multirow{3}{*}{ Histology } & Adenocarcinoma & & & 25 \\
\hline & Bronchioloalvéolar Carcinoma & & & 9 \\
\hline & Large Cell Carcinoma & & 4 & 5 \\
\hline \multirow{4}{*}{ Initial Staging } & I & 2 & 2 & 3 \\
\hline & II & 6 & 6 & 8 \\
\hline & III & 10 & 10 & 13 \\
\hline & IV & 59 & 59 & 76 \\
\hline
\end{tabular}


Table 3. Therapeutic modalities and clinical response.

\begin{tabular}{|c|c|c|c|c|c|c|c|c|}
\hline \multirow{2}{*}{\multicolumn{2}{|c|}{ Therapeutic Modalities }} & \multirow{2}{*}{ Number ( $n$ ) } & \multirow{2}{*}{$\%$} & \multicolumn{5}{|c|}{ Post therapeutic clinical response (\%) } \\
\hline & & & & Pain & Cough & Dysp & Hemop & PNS \\
\hline \multicolumn{2}{|c|}{ Surgery (Radical or partial) } & 3 & 4 & 4 & 0 & 0 & 0 & 3 \\
\hline \multicolumn{2}{|c|}{ Surgery + Chemo } & 6 & 8 & 4 & 0 & 1 & 0 & 2 \\
\hline \multicolumn{2}{|c|}{ Radiotherapy } & 0 & 0 & 0 & 0 & 0 & 0 & 0 \\
\hline \multicolumn{2}{|r|}{ Taxane + Platine } & 21 & 27 & 2 & 0 & 0 & 0 & 1 \\
\hline \multirow[t]{3}{*}{ Chemo (6 cures) } & Navelbine + Platine & 11 & 14 & 3 & 0 & 1 & 0 & 0 \\
\hline & 5FU + Platine & 23 & 30 & 4 & 1 & 0 & 1 & 0 \\
\hline & Erlotinib & 2 & 3 & 0 & 0 & 0 & 0 & 0 \\
\hline Target Therapies & $\begin{array}{c}\text { Taxane }+ \\
\text { Bevacizumab }\end{array}$ & 1 & 1 & 1 & 0 & 0 & 0 & 2 \\
\hline \multicolumn{2}{|c|}{ Palliatif care } & 10 & 13 & 5 & 4 & 1 & 0 & 3 \\
\hline \multicolumn{2}{|c|}{ Total } & 77 & 100 & 23 & 5 & 3 & 1 & 11 \\
\hline
\end{tabular}

Chemo: Chemotherapy, Dysp: Dyspnea, Hemop: Hemoptysis, PNS: paraneoplasic Syndrome.

Table 4. Treatment Response (Recist Criteria 2000).

\begin{tabular}{|c|c|c|c|c|c|}
\hline & Modalities & $\mathrm{CR}$ & PR & ST & PG \\
\hline & Surgery & 0 & 0 & 2 & 1 \\
\hline & Surgery + Chemo & 0 & 0 & 4 & 2 \\
\hline & Docetaxel-Platine & 0 & 3 & 5 & 13 \\
\hline \multirow[t]{5}{*}{ Chemo } & NAV-Platine & 0 & 2 & 4 & 5 \\
\hline & Platine-5FU & 0 & 3 & 4 & 16 \\
\hline & Erlotinib & 0 & 1 & 1 & 0 \\
\hline & Docetaxel -Beva & 0 & 0 & 1 & 0 \\
\hline & Palliative care & 0 & 0 & 0 & 10 \\
\hline
\end{tabular}

Chemo: Chemotherapy, NAV: Navelbine, 5FU: 5 Fluoro-uracile, Beva: Bevacizumab.

(4/6) and Navelbine-Platinum (4/6) regiments. Tumor progression was most commonly observed with Taxane-Platinum (13/55) and Platinum-5Fluoro-uracil (16/55) combinations (Table 4). Post-chemotherapy toxicities were mainly haematological and digestive in more than $30 \%$ of cases (Table 5). These were usually Grade 2 WHO criteria; resolving spontaneously or with treatment. Overall survival was 09 months (Figure 1).

\section{Discussion}

\subsection{General Patients' Characteristics}

The relative youth of the patients in our series is due to the socio-demographic characteristics of sub-Saharan African population. In Côte d'Ivoire, for example, the general census of the population carried out in 1998 and recently in 2014 showed that the Ivorian population was young [8]. However, this characteristic 
Table 5. Post chemotherapy tolerance caracteristics.

\begin{tabular}{ccccccc}
\hline & \multicolumn{7}{c}{ Toxicities } \\
\cline { 2 - 7 } & Hematological & Renal & Digestive & Neurological & Mucosa & Skin \\
\hline TAX-Platine $(\mathrm{n}=21)$ & $8(38 \%)$ & 0 & $7(33 \%)$ & $2(9 \%)$ & 0 & 0 \\
NAV-Platine $(\mathrm{n}=11)$ & $4(36 \%)$ & $2(18 \%)$ & $4(36 \%)$ & $1(9 \%)$ & 0 & 0 \\
5FU-Platine $(\mathrm{n}=23)$ & $9(39 \%)$ & $3(13 \%)$ & $3(13 \%)$ & 0 & $8(34 \%)$ & 0 \\
Erlotinib $(\mathrm{n}=2)$ & 0 & 0 & 0 & 0 & 0 & $2(100 \%)$ \\
TAX-Beva $(\mathrm{n}=1)$ & $1(100 \%)$ & 0 & 0 & 0 & 0 & 0 \\
\hline
\end{tabular}

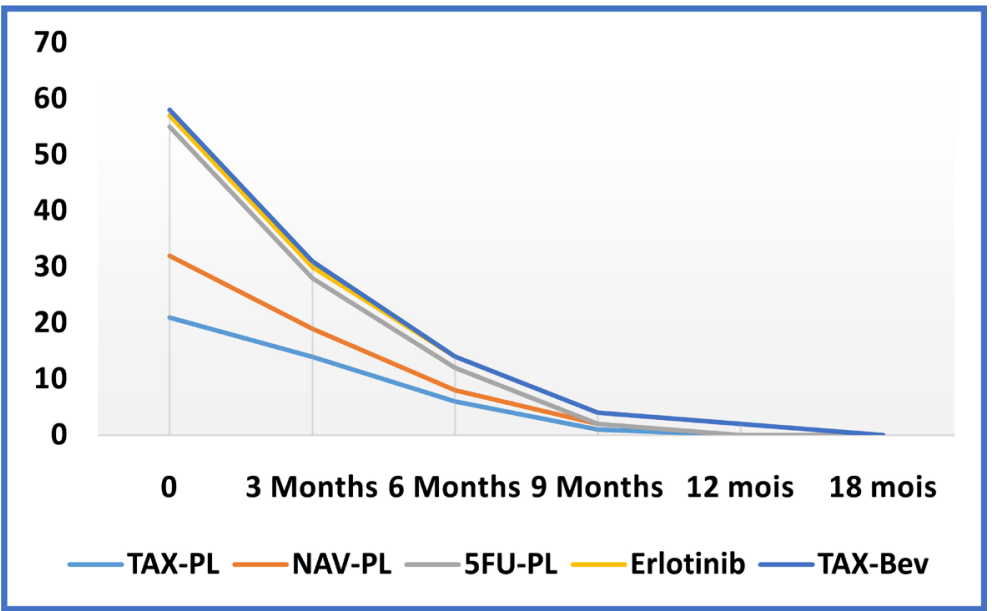

Figure 1. Overall survival rate.

could also be explained by the ever increasing incidence of smoking (passive and active) in our country [9]. Indeed, the between tobacco and the occurrence of non-small cell lung cancer has been established since the 1930s. Two large studies conducted one in the United States [10] and the other from general practitioners in Great Britain [11], have demonstrated the existence of a direct relationship between tobacco consumption and the occurrence of lung cancer with odds ratios of $9.1-12.8$ in humans and $2.1-3.3$ in women. NSCLC is essentially represented by squamous cell carcinoma. They are characterized by their clinical polymorphisms and are not correlated to any socio-cultural origin.

\subsection{Therapeutic Aspects}

Oncologic surgery is the therapeutic method that allows a definitive cure of NSCLC [12]. This surgery, supplemented if necessary by radiotherapy, also ensures satisfactory regional control. It does not, however, treat metastatic progression, especially if there is an extensive lymph node involvement [13]. Very few patients in our series received surgery and/or radiation therapy due to the advanced stage they were seen at. The factors related to this late diagnosis were multifaceted [3]. They were mainly socio-cultural factors and lack of financial means. Chemotherapy whether neoadjuvant, adjuvant or palliative helps improve patient survival rate. Cisplatin being the major anticancer drug used. 
These regiments have brought a significant gain to our patients and therefore an improvement in their quality of life. This improvement was also observed in various randomized trials comparing chemotherapy to exclusively symptomatic treatment. These studies have concluded to a significant advantage of chemotherapy versus symptomatic care [14]. In addition to these commonly used anticancer drugs in our daily practice, certain so-called new molecules, more often used in the western series, have given hope to patients resistant to more traditional treatments [15] such as Pemetrexed. The efficacy of which has been proven in a non-inferiority phase III study by Scaglioti et al. [15]. Targeted therapies were very rarely used in our series; due to their recent use in the management of NSCLC but also due to most of our patients' limited financial resources. However, Erlotinib, a tyrosine kinase inhibitor, has a recognized action in bronchopulmonary adenocarcinoma. In Western literature, other target therapies have already been tested in Phase III studies; Such as Cetuximab, which has shown benefits in first line treatment for metastatic NSCLC [16]. As for Bevacizumab, its use has been slowed due to the occurrence of severe toxicities in some patients [17].

\subsection{Tumor Response}

The tumor response in our series was modest due to lack of financial resources making access to certain molecules difficult and poor observance of inter cure time. Moreover, this histological entity is deemed to be poorly chemo sensitive. These results are seen in mostly African but also Western series [18].

\subsection{The Tolerance Profile}

The most frequent toxicities (hematological and digestive) are inherent to the different anticancer drugs used in our series. These were generally Taxanes with marked hematologic toxicity, especially in the white blood cell line [18]. As for Cisplatin, which is a major drug in NSCLC-specific treatment, it was responsible for neurological and renal toxicities [14]. The latter being almost constant, its administration requires hyperhydration with sodium and magnesium supplementation before and after chemotherapy [14]. Regarding neurological toxicities, pure sensory neuropathy was consistently observed above the cumulative dose of $600 \mathrm{mg} / \mathrm{m}^{2}$ [14]. These different toxicities observed in our study were spontaneously reversible in the majority of the cases and for some with help of some treatments such as hematopoietic growths factors in some cases.

\subsection{Survival}

Global Survival did not exceed nine (09) months in our context. Lung cancer is considered to be of poor prognosis. The factors of poor prognosis most often observed in our patients were tumor size, lymph node involvement and metastatic spread. This pejorative prognosis is also found in Western literature where phase III studies have shown survival rates not exceeding 11 months [19]. 


\section{Conclusions}

77 patients with NSCLC benefited from specific and/or non-specific therapies. In this relatively young age group of patients, our protocols have brought a clinical gain with an acceptable tolerance profile. However, no improvement in overall survival was observed denoting the pejorative character of NSCLC. The focus must therefore be on effective primary prevention represented by an effective fight against tobacco abuse.

Efforts are currently being made in Côte d'Ivoire to establish programs to fight against smoking, to ban smoking in public places and tobacco advertisement.

\section{References}

[1] Travis, W.D., et al. (1999) Histological Classification of Lung and Pleural Tumours. Histological Typing of Lung and Pleural Tumours, 3, 21-24. https://doi.org/10.1007/978-3-642-60049-4_2

[2] Pelletier, M.P., De B. Edwardes, M.D., Michel, R.P., Halwani, F. and Morin, J.E. (2001) Prognostic Markers in Resectable Non-Small Cell Lung Cancer: A Multivariate Analysis. Canadian Journal of Surgery, 44,180-188.

[3] Niang, A., Bonnichon, A., Ba-Fall, K., Dussart, C., Camara, P., Vaylet, F., Mbaye, P.S., L'Her, P., Sane, M. and Margery, J. (2001) Le cancer bronchique au Sénégal. MedecineTropicale, 67, 651-656.

[4] Ladanyi, M. and Pao, W. (2008) Lung Adenocarcinoma: Guiding EGFR-Targeted Therapy and Beyond. Modern Pathology, 21, 16-22. https://doi.org/10.1038/modpathol.3801018

[5] Culier, J.P.S., et al. (2008) Diagnostic the New TNM Classification for Lung Cancer. Revue des Maladies Respiratoires, 25, 3S40-3S47.

[6] Duffaud, F. and Therasse, P. (2000) Nouvelles recommandations pour l'évaluation de la réponse tumorale dans les tumeurs solides. Bull du cancer, 12, 881-886.

[7] Kaplan, E.L. and Meier, P. (1958) Non Parametric Estimation from Incomplete Observations. American Statistical Association, 53, 457-481. http://www.jstor.org/stable/2281868

[8] Ba, I., et al. (2014) Recensement général de la population et de l'habitat en Côte d'Ivoire: Rapport d'exécution et de présentation des principaux résultats. $R G P H, 4$, $1-49$.

[9] Doll, R., Peto, R., et al. (1978) Cigarette Smoking and Bronchial Carcinoma: Dose and Time Relationships among Regular Smokers and Lifelong Non-Smokers. J Epidemiology \& Community Health, 32, 303-313. https://doi.org/10.1136/jech.32.4.303

[10] Wynder, E. and Graham, E.A. (1950) Tobacco Smoking as a Possible Etiologic Factor in Bronchiogenic Carcinoma. A Study of Six Hundred and Eighty-Four Proved Cases. JAMA, 143, 329-346. https://doi.org/10.1001/jama.1950.02910390001001

[11] Doll, R. and Hill, A.B. (1952) A Study of the Aetiology of Carcinoma of Lung. British Medical Journal, 2, 1271-1286. https://doi.org/10.1136/bmj.2.4797.1271

[12] Al Kattan, K. and Goldstraw, P. (1995) Completion Pneumonectomy: Indications and Outcome. The Journal of Thoracic and Cardiovascular Surgery, 110, 1125-1129. 
https://doi.org/10.1016/S0022-5223(05)80182-5

[13] Donnadieu, N., Paesmans, M. and Sculier, J.P. (1991) Chimiothérapie des cancers bronchiques non à petites cellules: Meta-analyse de la littérature en fonction de l'extension de la maladie. Revue des maladies respiratoires, 8, 197-204.

[14] Scagliotti, G.V., Parikh, P., Von Pawel, J., et al. (2008) Phase III Study Comparing Cisplatin plus Gemcitabine with Cisplatin plus Premetrexed in Chemotherapy-Naive Patients with Advanced Stage Non-Small-Cell Jung Cancer. Journal of Clinical Oncology, 26, 3543-3551. https://doi.org/10.1200/JCO.2007.15.0375

[15] Edward, S.K., Ann, M.M., William, N.W., et al. (2009) A Phase 2 Study of Cetuximab in Combination with Docetaxel in Chemotherapy-Refractory/Resistant Patients with Advanced Nonsmall Cell Lung Cancer. Cancer, 115, 1713-1722. https://doi.org/10.1002/cncr.24148

[16] Johnson, D.H., Fehrenbacher, L., Novotny, W.F., et al. (2004) Randomized Phase II Trial Comparing Bevacizumab plus Cisplatin and Paclitaxel Alone in Previously Untreated Locally Advanced or Metastatic Non-Small-Cell Lung Cancer. Journal of Clinical Oncology, 22, 2184-2191. https://doi.org/10.1200/JCO.2004.11.022

[17] El Ouazzani, H., Menchafou, I., Achachi, L., El Ftouh, M. and El Fassy Fihry, M.T. (2010) Delay in the Diagnosis of Primary Bronchial Cancer. Study Carried out in the Pneumology Unit of Ibn Sina University Hospital, Rabat (Morocco). Revue de Pneumologie Clinique, 66, 335-341. https://doi.org/10.1016/j.pneumo.2010.02.004

[18] Pérol, M. and Pérol, D. (2004) The Role of Meta-Analysis in Assessing the Treatment of Advanced Non-Small Cell Lung Cancer. Revue de Pneumologie Clinique, 60, 29-37. https://doi.org/10.1016/S0761-8417(04)72080-5

[19] Blanchon, F., Grivaux, M., Zureik, M., et al. (2006) CohorteKbp-2000-Cphg: Evaluation des facteurs pronostiques de la survie du cancer bronchique primitif à 2 et 5 ans. Revue des Maladies Respiratoires, 23, 165-171. https://doi.org/10.1016/S0761-8425(06)71482-6 